\title{
Pediatric Septic Arthritis and Osteomyelitis in the USA: A National KID Database Analysis
}

\author{
Gabriella Safdieh, MS, MD • Jason Silberman, BA • Joseph Nguyen, MPH • Shevaun M. Doyle, MD • \\ John S. Blanco, MD • David M. Scher, MD • Daniel W. Green, MD, MS • Roger F. Widmann, MD • \\ Emily R. Dodwell, MD, MPH, FRCSC (D)
}

Received: 25 January 2018/Accepted: 3 October 2018/Published online: 12 November 2018

(C) Hospital for Special Surgery 2018

\begin{abstract}
Background: Prior reports suggest that osteoarticular infections may be increasing over time. Questions/Purposes: We sought to determine if incidence rates, median in-hospital costs, and length of stay (LOS) of osteomyelitis, septic arthritis (SA), and combined infections have changed over time for pediatric patients, and how they compare to previously reported rates. Methods: The Kids' Inpatient Database (KID), a US national sample of pediatric hospital discharge records from 1997, 2000, 2003, 2006, 2009, and 2012, was used to determine yearly estimated counts of infections in children 20 years of age or younger. US census data was used to calculate yearly incidence rates. Trend tests using linear contrast analysis were used to compare estimated median LOS and inflation-adjusted median costs over time for each type of infection. Results: From 1997 through 2012, the incidence rate of osteomyelitis increased from 7.9 to 10.5 per 100,000 , SA was unchanged from 5.3 to 5.2 per 100 , and
\end{abstract}

Level of Evidence: Level II, retrospective national database study

Electronic supplementary material The online version of this article (https://doi.org/10.1007/s11420-018-9644-2) contains supplementary material, which is available to authorized users.

G. Safdieh, MS, MD

Parsley Health,

33 Irving Place,

New York, NY 10003, USA

J. Silberman, BA

Weill Cornell Medical College,

New York, NY 10021, USA

J. Nguyen, MPH · S. M. Doyle, MD · J. S. Blanco, MD •

D. M. Scher, MD • D. W. Green, MD, MS • R. F. Widmann, MD •

E. R. Dodwell, MD, MPH, FRCSC ( $\square)$

Hospital for Special Surgery,

535 E 70th St,

New York, NY 10021, USA

e-mail: dodwelle@hss.edu combined infections increased from 0.8 to 1.3 per 100,000 . Median LOS from 1997 to 2012 showed no significant change for osteomyelitis (5.0 to 4.9 days), SA (4.4 to 4.1 days), or combined infections (6.5 to 6.8 days). Median in-hospital costs from 1997 to 2012 increased for osteomyelitis (\$7735 to $\$ 11,823)$, SA ( $\$ 5041$ to $\$ 10,574)$, and combined infections $(\$ 12,691$ to $\$ 16,260)$. Conclusion: In pediatric patients, the estimated incidence rate of SA appeared stable, while rates of osteomyelitis and combined infections increased. These estimated rates fall within previously reported ranges. Despite stable LOS, costs have increased over time.

Keywords septic arthritis - osteomyelitis. osteoarticular infections $\cdot$ KID database $\cdot$ LOS $\cdot$ cost

\section{Introduction}

Timely diagnosis and treatment are paramount to minimizing complications and optimizing outcomes in the treatment of septic arthritis (SA) and osteomyelitis. With appropriate treatment, many cases resolve without long-term complications, but some cases may be complicated by chronic infection, joint dislocation, growth arrest, limb deformity, avascular necrosis, deep venous thrombosis, joint degeneration, and even death $[4,19,32,36]$. Differences in the incidence and severity of osteoarticular infections, and the costs and lengths of hospital stay for their care, may be related to local pathogen profiles, virulence of the organism, treatment regimens, drug resistance, vaccination programs, immune-modifying drugs, medical comorbidities, and other factors [9].

The incidence rate of pediatric osteomyelitis has been reported at 1.94 to $13 / 100,000[6,13,33]$ and that of pediatric SA at 4 to 12 per $100,000[11,16,28,29]$. The epidemiology of osteoarticular infections is primarily based on retrospective cohorts, many from single institutions [2, 13, 14, 23, 33]. A previously published single-institution study of 554 children reported a 2.8 -fold increase in osteomyelitis over 20 years, with 
SA rates remaining constant [13]. Another single-institution study demonstrated a $24 \%$ change in the rate of acute osteomyelitis, from 11.5 per $100,000(95 \% \mathrm{CI}=4.15)$ in 1982 to 14.3 per $100,000(95 \% \mathrm{CI}=5.12)$ in 2003 [23]. Although most studies suggest that SA rates are static, one study reported an increased incidence of SA over time, proposing an increased number of arthroscopic surgeries as the cause [14]. A concern with singlecenter studies is that the denominator is not well defined. Infections per year can easily be modified by changes in catchment area for the hospital/institution or referral patterns.

Stockman et al. previously used the Kids' Inpatient Database (KID) to assess the national US epidemiology of osteoarticular infections [38]. A $15 \%$ increase in the rate of osteoarticular infections (from 2.07 to 2.38 cases per 1000 children admitted) was reported from 1997 through 2012 [12]. The rate of osteoarticular infections was calculated by dividing the number of children admitted for osteoarticular infections by 1000 children admitted for any diagnosis. The apparent increased rate of osteoarticular infections could be due to an increase in the number of admissions for osteoarticular infections and/or a decrease in admissions for other diagnoses. Thus, this previous KID analysis does not provide a true incidence rate or optimal clinically relevant results.

Length of stay (LOS), costs, and resource utilization relating to osteoarticular infections have been documented in the past. The median LOS for patients with osteomyelitis treated in 1982 to 1983 was 50 days and for patients treated in 2002 to 2003 was 29 days, although both time points could be considered historic [23]. The National Inpatient Sample demonstrated a trend toward decreased health care utilization for pediatric patients with SA from 1988 to 2000, but inflation-adjusted total charges increased over time, from a median total charge of $\$ 10,098$ in 1988 to $\$ 11,155$ in 2000 $(p<0.05)$; LOS was shorter for patients of higher socioeconomic status $(p<0.05)$ [12]. This previous analysis on financial aspects of osteoarticular infections was limited by reporting of charges, not costs.

The primary objective of the current study was to determine if national US incidence rates of osteomyelitis, SA, and both infections combined have increased over time and how they compare to previously reported rates. Secondary aims were to determine median in-hospital costs and LOS for each diagnosis and to assess how these have changed over time.

\section{Methods}

Data was sourced from the KID, a part of the Agency for Healthcare Research and Quality (AHRQ) Healthcare Cost and Utilization Project (HCUP). This all-payer inpatient database contains a US national weighted sample of more than seven million hospital admissions from approximately 1000 US hospitals for patients younger than 21 years of age. The traditional National Institutes of Health definition of pediatric is age less than 21 years; this database includes only pediatric patients. Datasets have been published for 1997, 2000, 2003, 2006, 2009, and 2012, and all published years were included in this study. Unweighted, the KID contains approximately three million discharge records each year. Based on sampling and weighting parameters, it is possible to determine national and regional estimates, despite the fact that not every US admission is included in this dataset. The database contains over 180 variables, including diagnoses by International Classification of Diseases, Ninth Revision, Clinical Modification (ICD-9-CM), procedures by ICD-9-CM, patient and hospital demographics, total charges, and LOS. A cost-to-charge ratio is provided in order to convert charges to costs. Diagnosis codes for osteomyelitis and SA and relevant procedure codes are listed (see Online Resource 1).

Yearly incidence rates of osteomyelitis, SA, and combined infections were ascertained using weighted frequency data from the KID database with population estimates calculated from intercensal bridged-race population estimates from the US Census and National Center for Health Statistics (NCHS) from the years 1990 to 2014 [39-42]. Incidence rates for each type of infection were calculated by age. Incidence rates by race could not be calculated accurately due to incomplete reporting of race in the KID.

Median LOS and inflation-adjusted costs were calculated for each infection type for each year. Total hospital charges were converted using hospital-level cost-to-charge ratios supplied by HCUP to estimate the cost of hospital stays. The costs were further adjusted to 2012 dollars by applying the medical care component of the consumer price index [7]. Procedures performed on included patients were also analyzed and compared over time. Trend tests using linear contrast analysis were used to compare estimated median LOS and inflation-adjusted cost over time for each type of infection. All statistical analyses were performed using SAS 9.3 (SAS Institute Inc., Cary, NC, USA). Significance was set at $p=0.05$.

\section{Results}

From 1997 to 2012, annual estimated cases increased for osteomyelitis (6524 to 9134), SA (4379 to 4485), and combined infections (624 to 1167$), p<0.05$. Weighted frequencies for patient sex are listed in Table 1 . For each year and each diagnosis, there were more males admitted than females. There were significantly more males with septic arthritis than females $(p=0.002)$, while distributions of osteomyelitis and combined infection between the sexes were not statistically significant $(p=0.155$ and $p=0.062$, respectively). Median age, LOS, and total cost are also presented (Table 1). The incidence rate of hospitalized cases of osteomyelitis increased by $33 \%$, from 7.9 to 10.5 per 100,000 $(p=0.015)$; SA hospitalization incidence rates were unchanged, at 5.3 to 5.2 per $100,000(p=0.917)$, and combined infections increased $63 \%$, from 0.8 per 100,000 to 1.3 per 100,000 ( $p=0.016$; Fig. 1$)$.

The incidence rates of osteoarticular infections by age are illustrated in Fig. 2. Post hoc pairwise comparison of mean age from year to year showed a significant increase in age between years 1997 to 2000 and 2000 to 2003 for OA and SA hospitalizations, but no increase in age from 2003 to 2006, 2006 to 2009, and 2009 to 2012. For hospitalizations for combined disease, there was no significant difference in mean age for each subsequent year of data. 
Table 1 Weighted descriptives of demographic, length of stay, and charge characteristics of pediatric hospitalizations for osteoarticular infections in the USA, 1997-2012

\begin{tabular}{|c|c|c|c|c|c|c|}
\hline Characteristic* & 1997 & 2000 & 2003 & 2006 & 2009 & 2012 \\
\hline Osteomyelitis $^{\mathrm{a}}$ & $\begin{array}{l}6524 \\
(6029,7200)\end{array}$ & $\begin{array}{l}7507 \\
(6810,8361)\end{array}$ & $\begin{array}{l}7737 \\
(6985,8633)\end{array}$ & $\begin{array}{l}9367 \\
(8266,10,681)\end{array}$ & $\begin{array}{l}9579 \\
(8417,10,942)\end{array}$ & $\begin{array}{l}9134 \\
(8135,10,430)\end{array}$ \\
\hline Female sex & $2474(38 \%)$ & $2744(37 \%)$ & $2668(35 \%)$ & $3316(36 \%)$ & $3531(37 \%)$ & $3279(36 \%)$ \\
\hline Age, years & $\begin{array}{l}7.8 \\
2.3-12.3\end{array}$ & $\begin{array}{l}9.4 \\
(2.7-13.9)\end{array}$ & $\begin{array}{l}10.2 \\
4.5-14.7\end{array}$ & $\begin{array}{l}10.0 \\
(3.9-14.7)\end{array}$ & $\begin{array}{l}10.2 \\
(3.7-15.2)\end{array}$ & $\begin{array}{l}10.5 \\
(5.0-15.0)\end{array}$ \\
\hline Length of stay, days & $\begin{array}{l}5.0 \\
(2.8-9.0)\end{array}$ & $\begin{array}{l}4.9 \\
(2.7-8.6)\end{array}$ & $\begin{array}{l}5.1 \\
(2.9-9.1)\end{array}$ & $\begin{array}{l}5.2 \\
(2.8-9.4)\end{array}$ & $\begin{array}{l}5.3 \\
(2.9-9.6)\end{array}$ & $\begin{array}{l}4.9 \\
(2.8-8.7)\end{array}$ \\
\hline Total cost USD, 2012 adjusted & $\begin{array}{l}\$ 7735 \\
(\$ 4531-19,553)\end{array}$ & $\begin{array}{l}\$ 6175 \\
(\$ 3819-11,081)\end{array}$ & $\begin{array}{l}\$ 8484 \\
(\$ 5226-14,854)\end{array}$ & $\begin{array}{l}\$ 9825 \\
(\$ 5832-17,389)\end{array}$ & $\begin{array}{l}\$ 10,945 \\
(\$ 6358-19,714)\end{array}$ & $\begin{array}{l}\$ 11,823 \\
(\$ 7079-21,294)\end{array}$ \\
\hline Septic arthritis ${ }^{\mathrm{a}}$ & $\begin{array}{l}4379 \\
(4152,4680)\end{array}$ & $\begin{array}{l}4798 \\
(4508,5142)\end{array}$ & $\begin{array}{l}4719 \\
(4437,5050)\end{array}$ & $\begin{array}{l}5172 \\
(4832,5568)\end{array}$ & $\begin{array}{l}4871 \\
(4570,5222)\end{array}$ & $\begin{array}{l}4485 \\
(4241,4795)\end{array}$ \\
\hline Female sex & $1799(41 \%)$ & $1797(37 \%)$ & $1668(36 \%)$ & $1798(35 \%)$ & $1790(37 \%)$ & $1631(36 \%)$ \\
\hline Age, years & $\begin{array}{l}5.2 \\
(1.0-10.6)\end{array}$ & $\begin{array}{l}6.5 \\
(1.4-12.7)\end{array}$ & $\begin{array}{l}7.6 \\
(2.0-13.3)\end{array}$ & $\begin{array}{l}7.4 \\
(1.9-14.3)\end{array}$ & $\begin{array}{l}7.1 \\
(1.8-14.2)\end{array}$ & $\begin{array}{l}8.2 \\
(2.8-14.4)\end{array}$ \\
\hline Length of stay, days & $\begin{array}{l}4.4 \\
(2.6-7.3)\end{array}$ & $\begin{array}{l}4.5 \\
(2.7-7.0)\end{array}$ & $\begin{array}{l}4.3 \\
(2.5-7.1)\end{array}$ & $\begin{array}{l}4.3 \\
(2.5-7.2)\end{array}$ & $\begin{array}{l}4.4 \\
(2.5-7.4)\end{array}$ & $\begin{array}{l}4.1 \\
(2.5-7.0)\end{array}$ \\
\hline Total cost USD, 2012 adjusted & $\begin{array}{l}\$ 5.041 \\
(\$ 3876-9704)\end{array}$ & $\begin{array}{l}\$ 6.113 \\
(\$ 3.941-9.757)\end{array}$ & $\begin{array}{l}\$ 7843 \\
(\$ 4988-11,944)\end{array}$ & $\begin{array}{l}\$ 8607 \\
(\$ 5444-14,422)\end{array}$ & $\begin{array}{l}\$ 10,103 \\
(\$ 6258-16,926)\end{array}$ & $\begin{array}{l}\$ 10,574 \\
(\$ 6684-17,644)\end{array}$ \\
\hline Combined infections $^{\mathrm{a}}$ & $\begin{array}{l}624 \\
(619,630)\end{array}$ & $\begin{array}{l}703 \\
(698,711)\end{array}$ & $\begin{array}{l}780 \\
(781,798)\end{array}$ & $\begin{array}{l}1034 \\
(1023,1053)\end{array}$ & $\begin{array}{l}1277 \\
(1258,1302)\end{array}$ & $\begin{array}{l}1167 \\
(1151,1189)\end{array}$ \\
\hline Female sex & $239(38 \%)$ & $218(31 \%)$ & $262(34 \%)$ & $375(36 \%)$ & $511(40 \%)$ & $406(35 \%)$ \\
\hline Age, years & $\begin{array}{l}4.7 \\
(0.4-9.8)\end{array}$ & $\begin{array}{l}5.3 \\
(0.4-11.7)\end{array}$ & $\begin{array}{l}7.1 \\
(1.6-11.6)\end{array}$ & $\begin{array}{l}7.7 \\
(1.8-12.1)\end{array}$ & $\begin{array}{l}6.5 \\
(1.3-11.7)\end{array}$ & $\begin{array}{l}8.2 \\
(2.8-14.4)\end{array}$ \\
\hline Length of stay, days & $\begin{array}{l}6.5 \\
(4.1-11.0)\end{array}$ & $\begin{array}{l}6.5 \\
(4.2-11.3)\end{array}$ & $\begin{array}{l}6.9 \\
(4.1-13.0)\end{array}$ & $\begin{array}{l}7.0 \\
(4.3-13.4)\end{array}$ & $\begin{array}{l}7.6 \\
(4.5-13.8)\end{array}$ & $\begin{array}{l}6.8 \\
(4.1-12.1)\end{array}$ \\
\hline Total cost USD, 2012 adjusted & $\begin{array}{l}\$ 12,691 \\
(\$ 8839-29,375)\end{array}$ & $\begin{array}{l}\$ 9430 \\
(\$ 6278-13,635)\end{array}$ & $\begin{array}{l}\$ 11,382 \\
(\$ 7290-19,369)\end{array}$ & $\begin{array}{l}\$ 14,123 \\
(\$ 9378-27,519)\end{array}$ & $\begin{array}{l}\$ 17,314 \\
(\$ 10,158-32,410)\end{array}$ & $\begin{array}{l}\$ 16,260 \\
(\$ 10,103-30,264)\end{array}$ \\
\hline
\end{tabular}

*Age, length of stay, and total cost presented as weighted median (interquartile range)

${ }^{a}$ Overall weighted frequency (95\% confidence interval)

In 1997, 51\% of osteomyelitis patients underwent one or more surgical procedures. Procedures included bone debridement (59\%), diagnostic biopsy/aspiration (45\%), other debridement (24\%), joint debridement (19\%), and implant removal (6\%) (Table 2). Of those with SA, 78\% underwent a surgical procedure, including joint debridement (53\%) and diagnostic biopsy or aspiration (44\%), and $81 \%$ of patients with combined osteomyelitis and SA underwent a procedure; the most common were joint debridement (54\%), followed by diagnostic biopsy or aspiration (44\%) and bone debridement (36\%)
(Table 2). There was no significant change in proportion of patients undergoing a surgical procedure over the course of the study for osteomyelitis $(p=0.766)$ or combined infections $(p=0.399)$. However, there was a small but significant increase in the proportion of patients undergoing a surgical procedure for SA $(p=0.003)$ over the 15 -year study period.

Median LOS from 1997 to 2012 showed no significant change for osteomyelitis (5.0 to 4.9 days, $p=0.141$ ), SA (4.4 to 4.1 days, $p=0.478$ ), or combined infections (6.5 to 6.8 days, $p=0.575$ ) (Fig. 3; Table 1).

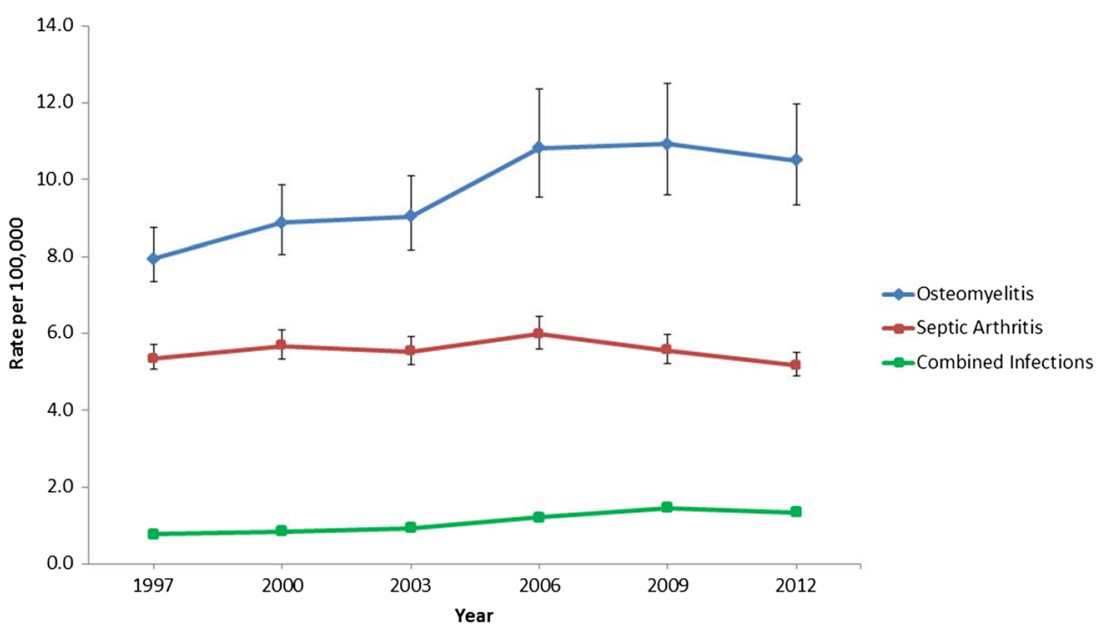

Fig. 1. Incidence of osteomyelitis, septic arthritis, and combined infections, 1997-2012 (error bars indicate 95\% confidence intervals; error bars for combined infections are not visible due to small error ranges) 


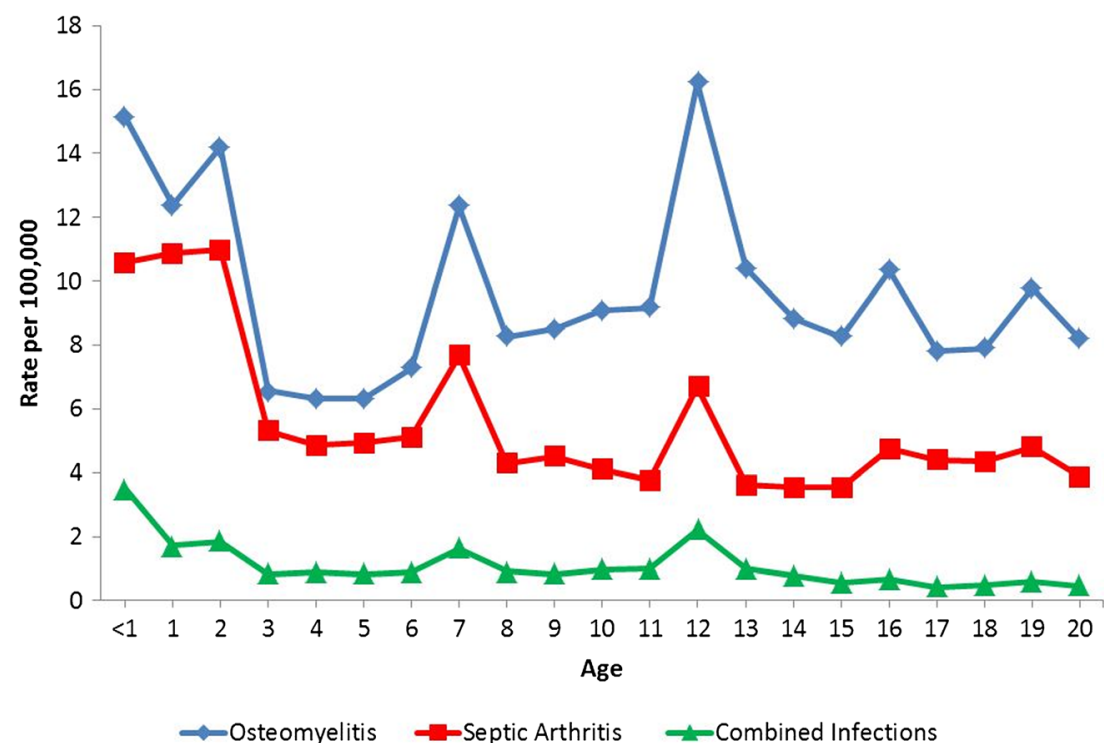

Fig. 2. Osteomyelitis, septic arthritis, and combined infection rate by age, for all years, 1997-2012

Adjusted median in-hospital costs in 1997 were $\$ 7735$ for osteomyelitis, $\$ 5041$ for SA, and $\$ 12,691$ for combined infections. By 2012 , these costs increased to $\$ 11,823$ for osteomyelitis $(p<0.001), \$ 10,574$ for SA $(p<0.001)$, and $\$ 16,260$ for both infections $(p<0.001)$. Controlling for inflation, costs increased significantly over the study period for all infection types ( $p<0.001$; Fig. 4$)$.

\section{Discussion}

The incidence rate of pediatric osteomyelitis increased by $33 \%$, while SA rates were stable, and combined infections increased by 63\% from 1997 to 2012. Despite stable LOS in all subgroups, costs for SA, osteomyelitis, and combined infections increased dramatically over the study period.
This study has a number of limitations. First, the administrative nature of the KID increases the possibility of misclassification due to hospital coding errors. However, multiple sources have validated the use of this database, which has been used to study temporal trends in various populations and validated against other sources [21, 37]. If misclassification were to occur, the most likely scenario is that a case of true infection was coded as unspecified infection or unspecified arthritis and thus would not have been included in our analysis. This would have resulted in underreporting of infection rates; therefore, the numbers reported here could be considered conservative. Second, because the KID database is cross-sectional and does not include longitudinal follow-up, it was not possible to assess for recurrence, late development of osteomyelitis, or additional surgical procedures required beyond the index admission.

Table 2 Procedures performed for osteoarticular infection, 1997-2012

\begin{tabular}{|c|c|c|c|c|c|c|c|}
\hline Infection type & Procedure $^{\mathrm{a}}$ & 1997 & 2000 & 2003 & 2006 & 2009 & 2012 \\
\hline \multirow[t]{6}{*}{ Osteomyelitis } & Procedure performed & $302(51 \%)$ & $3725(50 \%)$ & $3795(49 \%)$ & $4580(49 \%)$ & $4840(51 \%)$ & $4602(50 \%)$ \\
\hline & Bone debridement & $1942(59 \%)$ & $2199(59 \%)$ & $2385(63 \%)$ & $2841(62 \%)$ & $3105(64 \%)$ & $2916(63 \%)$ \\
\hline & Diagnostic biopsy or aspiration & $1501(45 \%)$ & $1637(44 \%)$ & $1522(40 \%)$ & $1780(39 \%)$ & $1902(39 \%)$ & $1804(39 \%)$ \\
\hline & Other debridement & $799(24 \%)$ & $818(22 \%)$ & $859(23 \%)$ & $874(19 \%)$ & $858(18 \%)$ & $899(20 \%)$ \\
\hline & Joint debridement & $615(19 \%)$ & $681(18 \%)$ & $742(20 \%)$ & $940(21 \%)$ & $1058(22 \%)$ & $1043(23 \%)$ \\
\hline & Removal of implant & $214(6 \%)$ & $322(9 \%)$ & $370(10 \%)$ & $407(9 \%)$ & $529(11 \%)$ & $464(10 \%)$ \\
\hline \multirow[t]{6}{*}{ Septic arthritis } & Procedure performed & $3400(78 \%)$ & $3850(80 \%)$ & $3790(80 \%)$ & $4085(79 \%)$ & $3979(82 \%)$ & $3707(93 \%)$ \\
\hline & Bone debridement & $629(14 \%)$ & $689(14 \%)$ & $793(17 \%)$ & $921(18 \%)$ & $1051(22 \%)$ & $1026(23 \%)$ \\
\hline & Diagnostic biopsy or aspiration & $1923(44 \%)$ & $1932(40 \%)$ & $1912(41 \%)$ & $1984(38 \%)$ & $1887(39 \%)$ & $1778(40 \%)$ \\
\hline & Other debridement & $408(9 \%)$ & $343(7 \%)$ & $346(7 \%)$ & $419(8 \%)$ & $367(8 \%)$ & $407(9 \%)$ \\
\hline & Joint debridement & $2338(53 \%)$ & $2796(58 \%)$ & $2784(59 \%)$ & $3033(59 \%)$ & $3040(62 \%)$ & $2820(63 \%)$ \\
\hline & Removal of implant & $17(0 \%)$ & $36(1 \%)$ & $58(1 \%)$ & $66(1 \%)$ & $72(1 \%)$ & $68(2 \%)$ \\
\hline \multirow[t]{6}{*}{ Combined infections } & Procedure performed & $507(81 \%)$ & $575(82 \%)$ & $669(85 \%)$ & $833(80 \%)$ & $1055(83 \%)$ & $992(85 \%)$ \\
\hline & Bone debridement & $224(36 \%)$ & $225(32 \%)$ & $287(36 \%)$ & $326(31 \%)$ & $521(41 \%)$ & $480(41 \%)$ \\
\hline & Diagnostic biopsy or aspiration & $268(43 \%)$ & $304(43 \%)$ & $346(44 \%)$ & $397(38 \%)$ & $532(42 \%)$ & $474(41 \%)$ \\
\hline & Other debridement & $90(14 \%)$ & $82(12 \%)$ & $85(11 \%)$ & $89(9 \%)$ & $120(9 \%)$ & $156(13 \%)$ \\
\hline & Joint debridement & $337(54 \%)$ & $398(57 \%)$ & $463(59 \%)$ & $583(56 \%)$ & $743(58 \%)$ & $690(59 \%)$ \\
\hline & Removal of implant & $3(0 \%)$ & $9(1 \%)$ & $13(2 \%)$ & $17(2 \%)$ & $25(2 \%)$ & $21(2 \%)$ \\
\hline
\end{tabular}

\footnotetext{
${ }^{a}$ See Appendix A for categorization of procedures
} 


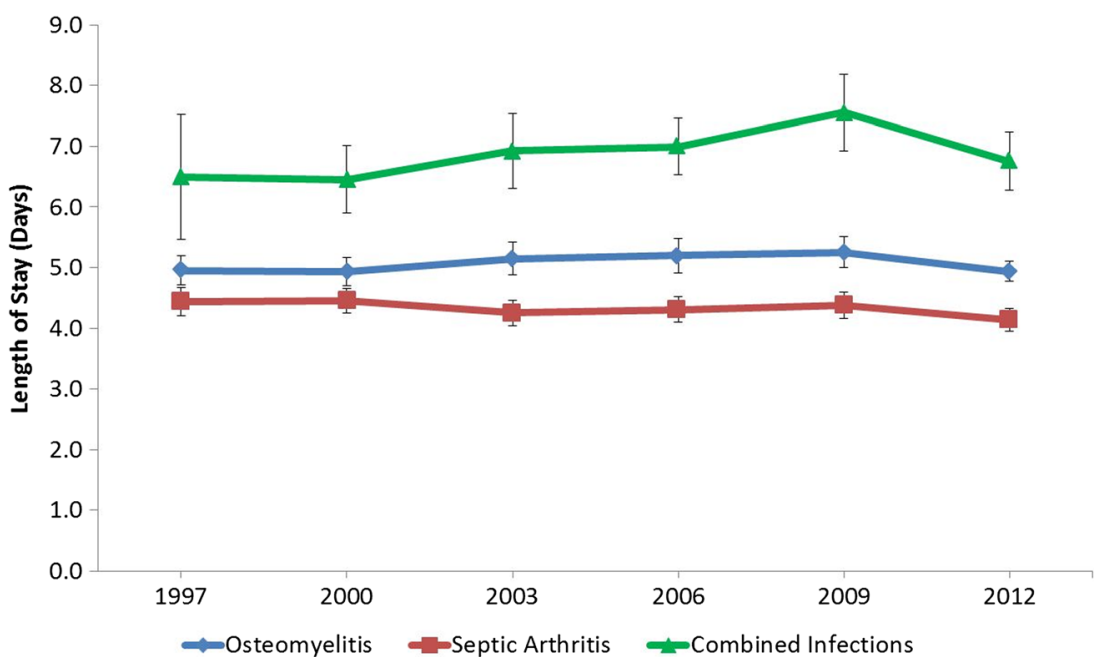

Fig. 3. Length of hospital stay for osteomyelitis, septic arthritis, and combined infections, 1997-2012

Third, the KID database does not provide accurate information on causative bacteria, as ICD-9 codes do not exist for every type of bacterial infection. Even where codes do exist for infection due to a specific bacteria (for example, septic arthritis of the knee caused by Staphylococcus aureus [ICD9 code 711.06 and 041.10], or septic arthritis of the knee caused by methicillin-resistant $S$. aureus [MRSA; ICD-9 code 711.06 and 041.12], we believe it would not be coded accurately because many clinicians/coders would likely select the more general code (septic arthritis of the knee, ICD9 code 711.06), without the additional code specifying the bacterial type. Fourth, despite an attempt to accurately calculate national incidence rates, the US Census numbers used for incidence rate calculations do not include undocumented residents, thus the actual denominator could be larger than indicated by census data. Fifth, information on length of antibiotic treatment, transition times to oral antibiotics, and intensive care unit (ICU) admission were not available in the KID database. Finally, this study may not have captured changes in practice that could have resulted from recent studies documenting shorter treatment regimens, as the most recent year included in the KID dataset was 2012.

Although we used the same data set as Stockmann et al. [38], the analyses differ significantly. Stockman et al. identified cases using the ICD-9-CM codes 711.0 (pyogenic arthritis), 730.0 (acute osteomyelitis), and 730.2 (unspecified osteomyelitis), as compared to the extensive list of ICD9-CM codes related to osteoarticular infections included in the current study (Online Resource 1). In addition, Stockmann et al. reported rates as cases per 1000 hospital admissions, which is perhaps a less useful statistic than an incident rate reported per 100,000 children.

The osteomyelitis rate identified in the current study was 7.9 to $10.5 / 100,000$, which falls within the ranges reported in other series in developed countries, 1.94 [13] to $13[33] / 100,000[6,13,33]$. Our reported rates are lower than those found in some populations, such as children from New Zealand or of Polynesian or Maori descent $(43 / 100,000)$ [34] and Aboriginal Australians (almost 200/100,000) [15].

The SA rate identified in this study was 4.3 to $5.2 /$ 100,000 , within but at the low end of the range reported in

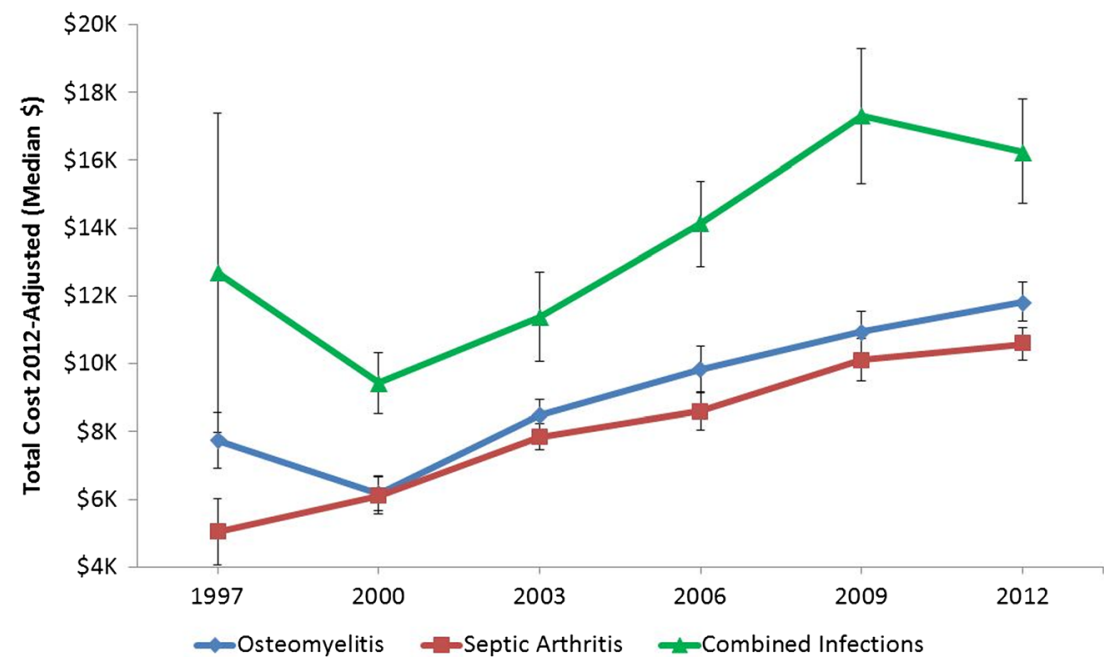

Fig. 4. Total cost associated with osteomyelitis, septic arthritis, and combined infections, 1997-2012 
other series, 4 to $12 / 100,000[11,16,29]$. The current series is limited only to infections treated in-hospital and does not include cases that may have been treated on an out-patient basis. However, it is unlikely that we have missed any significant cases of osteomyelitis, SA, or combined infections because they are typically treated in-hospital for at least a few days.

This study builds on previous studies similarly identifying an increasing rate of osteomyelitis and combined infections $[2,13,23]$. Although increasing bacterial virulence or some other factor may be causing this increase in osteomyelitis and combined infections, another likely explanation is that magnetic resonance imaging (MRI) evaluation is more accessible, making it easier to identify subtle disease, providing an apparent increase in the national rate of osteomyelitis and combined infections. Experts suggest that musculoskeletal infection imaging workup should include MRI rather than ultrasound, provided that imaging can be performed in a safe and timely fashion [24]. Additionally, when MRI is performed for suspected osteomyelitis, dedicated imaging of the neighboring joints should routinely be included.

LOS for osteoarticular infections has certainly improved from historic reports of 50 days in 1982 to 1983 [23] but has been stable at approximately 5 days over the course of this study. LOS is lower than in other recent reports, including a retrospective cohort study in Israel that found an overall LOS of $9.2 \pm 6.5$ days [6]. The decrease in LOS between previous reports and the current study period may be attributed in part to shorter IV antibiotic regimens, as SA traditionally was treated with a 2to 4-week treatment of IV antibiotics [8, 27, 44], while traditionally osteomyelitis was treated with antibiotics for 1 to 2 months, IV for the first 1 to 2 weeks. A recent Finnish randomized, controlled trial (RCT) treated children with 2 to 4 days of IV antibiotics then randomized children with SA to 10 or 30 days of clindamycin or a first-generation cephalosporin (intravenously for the first 2 to 4 days) [30]. Given no difference in outcomes between treatment arms, this regimen of short-course IV antibiotics followed by 10 days of oral antibiotics has been recommended [29].

In a similar Finnish RCT of children with culturepositive acute hematogenous osteomyelitis (AHOM), children were treated with 2 to 4 days of IV antibiotics, followed by randomization to clindamycin or a first-generation cephalosporin for 20 versus 30 days [31]. In an Australian prospective study of pediatric SA and osteomyelitis, 59\% of patients could be converted to oral antibiotics at 3 days and $86 \%$ at 5 days, with median LOS at 5 days [20]. Although these studies were completed in Finnish and Australian populations, their findings may influence osteoarticular treatment practices beyond those countries' borders.

With the Finnish studies including only uncomplicated SA and osteomyelitis cases, with no MRSA cases $[30,31]$, some may question the external validity of this study. When MRSA is present or C-reactive protein levels are persistently high despite antibiotic treatment, longer courses of IV antibiotics may be needed [22]. With these previous studies being performed in Europe and Australia, and results not having been replicated in North America or other countries, these shorter IV regimens may not have been fully adopted worldwide.

Early diagnosis, improved surgical management, more effective antibiotics, or greater access to home IV programs may also factor in the decreased LOS seen in previous studies, although the current study cannot prove this, since procedure rates were stable over the study period. Realistically, LOS probably cannot be reduced much beyond 5 days, since patients typically require at least 2 to 4 days of IV antibiotics, and most clinicians prefer to observe for fevers and C-reactive protein re-evaluation before discharge on oral antibiotics $[3,5]$.

Despite stable LOS over the study period, costs have increased over time in the USA, higher than the 3.0\% national growth rate in per-capita healthcare expenditures, specifically compared to the overall annual expenditure per capita from 2010 to 2011, 2011 to 2012, and 2012 to 2013, which was $4,3.7$, and $3.9 \%$, respectively [1] $(7.9,4.5$, and $4.6 \%$, respectively, in the 18 and younger population). This is consistent with the Nationwide Inpatient Sample study [12] that found that although efforts to reduce SA-associated LOS have been successful, they have not resulted in decreased hospital charges - perhaps partly due to the larger number of therapeutic procedures, diagnostic tests, or increased incidence of MRSA or other more virulent infections $[10,17,18,35,43]$. The emergence of MRSA in hospitals has been associated with increased rates of bacteremic infections caused by difficult-to-treat pathogens [25]. Patients with MRSA more commonly have sequelae from their musculoskeletal infections, often requiring ICU admission [35]. Assertions that decreasing LOS by promoting earlier hospital discharge would significantly reduce the overall hospital charges [26] are not supported by our current analysis.

In conclusion, pediatric osteoarticular infections are responsible for significant resource use. Across the USA, the incidence rate of SA was stable, while rates of osteomyelitis alone and combined infections increased. Despite stable LOS over the past 15 years, costs have increased. This study demonstrates the most accurate and current population-level data available on the incidence of osteoarticular infections in children and the changes in rates, LOS, and costs over time in the USA. Understanding current practices and the financial impact on our healthcare system may help in designing studies and public health initiatives aiming to optimize treatment and costs for patients with osteoarticular infections.

\section{Compliance with Ethical Standards}

Conflict of Interest: Gabriella Safdieh, MD, Jason Silberman, BA, Joseph Nguyen, MPH, Shevaun Doyle, MD, John Blanco, MD, David Scher, MD, Daniel Green, MD, MS, Roger Widmann, MD, and Emily Dodwell, MD, MPH, FRCSC, declare that they have no conflict of interest. Joseph Nguyen, MPH, reports grants from Clinical Translational Science Center (CTSC), National Center for Advancing Translational Sciences (NCATS), outside the submitted work. 
Human/Animal Rights: N/A

Informed Consent: N/A

Required Author Forms Disclosure forms provided by the authors are available with the online version of this article.

\section{References}

1. 2013 Health Care Cost and Utilization Report. Washington DC 2014. Available from https://www.healthcostinstitute.org/images/ pdfs/2013-HCCUR-12-17-14.pdf.

2. Arnold SR, Elias D, Buckingham SC, et al. Changing patterns of acute hematogenous osteomyelitis and septic arthritis: emergence of community-associated methicillin-resistant Staphylococcus aureus. J Pediatr Orthop. 2006;26(6):703-708.

3. Arnold JC, Cannavino CR, Ross MK, et al. Acute bacterial osteoarticular infections: eight-year analysis of $\mathrm{C}$-reactive protein for oral step-down therapy. Pediatrics. 2012;130(4):e821-8.

4. Benvenuti M, An T, Amaro E, et al. Double-edged sword: musculoskeletal infection provoked acute phase response in children. Orthop Clin N Am. 2017;48(2):181-197.

5. Chou ACC, Mahadev A. The use of C-reactive protein as a guide for transitioning to oral antibiotics in pediatric osteoarticular infections. J Pediatr Orthop. 2016;36(2):173-177.

6. Cohen E, Lifshitz K, Fruchtman Y, Eidelman M, Leibovitz E. Current data on acute haematogenous osteomyelitis in children in Southern Israel: epidemiology, microbiology, clinics and therapeutic consequences. Int Orthop. 2016;40(9):1987-1994.

7. Crawford M, Church J, Akin B. CPI Detailed Report - United States Bureau of Labor Statistics; 2015. Available from http:// data.bls.gov/pdq/SurveyOutputServlet.

8. Dagan R. Management of acute hematogenous osteomyelitis and septic arthritis in the pediatric patient. Pediatr Infect Dis J. 1993;12(1):88-92.

9. Dartnell J, Ramachandran M, Katchburian M. Haematogenous acute and subacute paediatric osteomyelitis: a systematic review of the literature. J Bone Joint Surg Br. 2012;94(5):584-595.

10. de Kraker MEA, Wolkewitz M, Davey PG, et al. Clinical impact of antimicrobial resistance in European hospitals: excess mortality and length of hospital stay related to methicillin-resistant Staphylococcus aureus bloodstream infections. Antimicrob Agents Chemother. 2011;55(4):1598-1605.

11. Dodwell ER. Osteomyelitis and septic arthritis in children: current concepts. Curr Opin Pediatr. 2013;25(1).

12. Freedman J, Guller U, Benjamin DK, et al. National trends in health care utilization and racial and socioeconomic disparities in pediatric pyogenic arthritis. J Pediatr Orthop. 2006;26(6):709715.

13. Gafur OA, Copley LAB, Hollmig ST, Browne RH, Thornton LA, Crawford SE. The impact of the current epidemiology of pediatric musculoskeletal infection on evaluation and treatment guidelines. J Pediatr Orthop. 2008;28(7):777-785.

14. Geirsson AJ, Statkevicius S, Vikingsson A. Septic arthritis in Iceland 1990-2002: increasing incidence due to iatrogenic infections. Ann Rheum Dis. 2008;67(5):638-643.

15. Gillespie WJ. The epidemiology of acute haematogenous osteomyelitis of childhood. Int J Epidemiol. 1985;14(4):600-606.

16. Gillespie WJ. Epidemiology in bone and joint infection. Infect Dis Clin N Am. 1990;4(3):361-376.

17. Goergens ED, McEvoy A, Watson M, Barrett IR. Acute osteomyelitis and septic arthritis in children. J Paediatr Child Health. 41(1-2):59-62.

18. Hawkshead JJ, Patel NB, Steele RW, Heinrich SD. Comparative severity of pediatric osteomyelitis attributable to methicillinresistant versus methicillin-sensitive Staphylococcus aureus. J Pediatr Orthop. 29(1):85-90.
19. Ilharreborde B. Sequelae of pediatric osteoarticular infection. Orthop Traumatol Surg Res. 2015;101(1):S129-S137.

20. Jagodzinski NA, Kanwar R, Graham K, Bache CE. Prospective evaluation of a shortened regimen of treatment for acute osteomyelitis and septic arthritis in children. J Pediatr Orthop. 2009;29(5):518-525.

21. Lee GE, Lorch SA, Sheffler-Collins S, Kronman MP, Shah SS. National hospitalization trends for pediatric pneumonia and associated complications. Pediatrics. 2010;126(2):204-213.

22. Liu C, Bayer A, Cosgrove SE, et al. Clinical practice guidelines by the infectious diseases society of america for the treatment of methicillin-resistant Staphylococcus aureus infections in adults and children: executive summary. Clin Infect Dis. 2011;52(3):285-292.

23. Malcius D, Trumpulyte G, Barauskas V, Kilda A. Two decades of acute hematogenous osteomyelitis in children: are there any changes?. Pediatr Surg Int. 2005;21(5):356-359.

24. Monsalve J, Kan JH, Schallert EK, Bisset GS, Zhang W, Rosenfeld SB. Septic arthritis in children: frequency of coexisting unsuspected osteomyelitis and implications on imaging work-up and management. Am J Roentgenol. 2015;204(6):1289-1295.

25. Murillo O, Grau I, Lora-Tamayo J, et al. The changing epidemiology of bacteraemic osteoarticular infections in the early $21 \mathrm{st}$ century. Clin Microbiol Infect. 2015;21(3):254.e1-8.

26. Nathwani D. Impact of methicillin-resistant Staphylococcus aureus infections on key health economic outcomes: does reducing the length of hospital stay matter? J Antimicrob Chemother. 2003;51 Suppl 2:ii37-44.

27. Nelson JD. The bacterial etiology and antibiotic management of septic arthritis in infants and children. Pediatrics. 1972;50(3):437440.

28. Okubo Y, Nochioka K, Marcia T. Nationwide survey of pediatric septic arthritis in the United States. J Orthop. 2017;14(3):342-346.

29. Paakkonen M, Peltola H. Treatment of acute septic arthritis. Pediatr Infect Dis J. 2013;32(6):684-685.

30. Peltola H, Pääkkönen M, Kallio P, Kallio MJT, OsteomyelitisSeptic Arthritis (OM-SA) Study Group. Prospective, randomized trial of 10 days versus 30 days of antimicrobial treatment, including a short-term course of parenteral therapy, for childhood septic arthritis. Clin Infect Dis. 2009;48(9):1201-1210.

31. Peltola H, Pääkkönen M, Kallio P, Kallio MJT, OsteomyelitisSeptic Arthritis Study Group. Short- versus long-term antimicrobial treatment for acute hematogenous osteomyelitis of childhood. Pediatr Infect Dis J. 2010;29(12):1123-1128.

32. Pendleton A, Kocher MS. Methicillin-resistant Staphylococcus aureus bone and joint infections in children. J Am Acad Orthop Surg. 2015;23(1):29-37.

33. Riise OR, Kirkhus E, Handeland KS, et al. Childhood osteomyelitis-incidence and differentiation from other acute onset musculoskeletal features in a population-based study. BMC Pediatr. 2008;8:45.

34. Rossaak M, Pitto RP. Osteomyelitis in Polynesian children. Int Orthop. 2005;29(1):55-58.

35. Sarkissian EJ, Gans I, Gunderson MA, Myers SH, Spiegel DA, Flynn JM. Community-acquired methicillin-resistant Staphylococcus aureus musculoskeletal infections: emerging trends over the past decade. J Pediatr Orthop. 36(3):323-327.

36. Schaub RL, Rodkey ML. Deep vein thrombosis and septic pulmonary emboli with MRSA osteomyelitis in a pediatric patient. Pediatr Emerg Care. 2012;28(9):911-912.

37. Simon TD, Berry J, Feudtner C, et al. Children with complex chronic conditions in inpatient hospital settings in the United States. Pediatrics. 2010;126(4):647-655.

38. Stockmann C, Ampofo K, Pavia AT, et al. National trends in the incidence, outcomes and charges of pediatric osteoarticular infections, 1997-2012. Pediatr Infect Dis J. 2015;34(6):672-674.

39. U.S. Department of Health and Human Services; Centers for Disease Control and Prevention; National Center for Health Statistics. Bridged-Race Population Estimates, United States July 1st Resident Population by State, County, Age, Sex, Bridged-Race, and Hispanic Origin. Compiled from 1990-1999 Bridged-Race Intercensal Population Estimates; 2004. Available from http://wonder.cdc.gov/bridged-race-v2014.html. 
40. U.S. Department of Health and Human Services; Centers for Disease Control and Prevention; National Center for Health Statistics. Bridged-Race Population Estimates, United States July 1st Resident Population by State, County, Age, Sex, Bridged-Race, and Hispanic Origin. Revised Bridged-Race 2000-2009 Intercensal Population Estimates; 2012. Available from http://wonder.cdc.gov/bridged-race-v2014.html.

41. U.S. Department of Health and Human Services; Centers for Disease Control and Prevention; National Center for Health Statistics. Intercensal Estimates of the Resident Population of the United States for July 1, 2000-July 1, 2009, by Year, County, Single-Year of Age $(0,1,2, . ., 85$ Years and over), Bridged Race, Hispanic Origin, and Sex; 2012. Available from http:// www.cdc.gov/nchs/nvss/bridged_race.htm.
42. U.S. Department of Health and Human Services; Centers for Disease Control and Prevention; National Center for Health Statistics. Bridged-Race Population Estimates, United States July 1st Resident Population by State, County, Age, Sex, Bridged-Race, and Hispanic Origin. Bridged-Race Vintage 2014 (2010-2014) Postcensal Population Estimates; 2015. Available from https://wonder.cdc.gov/bridged-race-v2017.html.

43. Vander Have KL, Karmazyn B, Verma M, et al. Communityassociated methicillin-resistant Staphylococcus aureus in acute musculoskeletal infection in children: a game changer. J Pediatr Orthop. 2009;29(8):927-931.

44. Welkon CJ, Long SS, Fisher MC, Alburger PD. Pyogenic arthritis in infants and children: a review of 95 cases. Pediatr Infect Dis. 1986;5(6):669-676. 